\title{
Shape Optimization of Damaged Columns Subjected to Conservative and Non-Conservative Forces
}

\author{
S. K. Jatav* and P. K. Datta** \\ Department of Aerospace Engineering, Indian Institute of Technology, Kharagpur-721302, India
}

\begin{abstract}
This paper deals with the development of a realistic shape optimization of damaged columns that are subjected to conservative and non-conservative forces, using the Genetic Algorithm (GA). The analysis is based on the design of the most optimized shape of the column under the constraint of constant weight, considering the Static, Vibrational, and Flutter characteristics. Under the action of conservative and non-conservative longitudinal forces, an elastic column loses its stability. A numerical analysis based on FEM has been performed on a uniform damaged column, to compute the fundamental buckling load, vibration frequency, and flutter load, under various end restraints. An optimization search based on the Genetic Algorithm is then executed, to find the optimal shape design of the column. The optimized column references the one having the highest buckling load, highest vibration frequency, and highest flutter load, among all the possible shapes of the column, for a given volume. A comparison is then made between the values obtained for the optimized damaged column, and those obtained for the optimized undamaged column. The comparison reveals that the incorporation of damage in the column alters its optimal shape to only a certain extent. Also, the critical load and frequency values for the optimized damaged column are comparatively low, compared with those obtained for the optimized undamaged column. However, these results hold true only for moderate-intensity damage cases. For high intensity damage, the optimal shape may not remain the same, and may vary, according to the severity of damage.
\end{abstract}

Key words: Shape Optimization, Non-conservative system, Flutter, Damage, Genetic Algorithm

\section{Introduction}

This paper studies a GA-based optimization algorithm for the discrete shape design of a damaged column having different end constraints, with the maximum buckling load and frequency of the first mode, for a conservative system. Numerical calculations to get the discrete shape design of the column with a circular cross-section for buckling load and fundamental frequency maximization are performed, under the three basic support conditions of a column, viz. clampedfree (C/F); clamped-simply supported (C/S); and simply supported (S/S).

The non-conservative problem involves the analysis of a damaged $\mathrm{C} / \mathrm{F}$ column, subjected to a tangential follower force at the free end. A C/F column, subjected to a tangential follower force at the free end, is referred to as beck's column (Bolotin, 1963). At a certain critical value of the force, Beck's column dynamically loses its stability, through a phenomenon called self-excited oscillations, which is referred to as flutter (Bolotin, 1963; Evan-Ivanowski, 1976). Elishakoff (2005) criticized the existence of a follower force. Sugiyama et al. (1999) described the appearance of realistic follower forces in engineering structures. Recent advances in the field of the aeroelastic behaviour of aerospace structures under follower loads have been reviewed and discussed by Datta and Biswas (2011).

Ishida and Sugiyama (1995) proposed a genetic based algorithm for the shape design of the strongest column. They observed that the buckling load ratio (eigenvalue ratio) of the searched column to the uniform one for the $\mathrm{C} / \mathrm{F}$ and
This is an Open Access article distributed under the terms of the Creative Commons Attribution Non-Commercial License (http://creativecommons.org/licenses/by$\mathrm{nc} / 3.0 /$ ) which permits unrestricted non-commercial use, distribution, and reproduction in any medium, provided the original work is properly cited. (cc) * Research Student

** Professor, Corresponding author: pkdatta@aero.iitkgp.ernet.in 
C/S condition reached 1.32 and 1.31 , respectively. The optimization of Beck's column on the basis of the maximum buckling load is found in the literature (Hanaoka and Washizu, 1980; Langthjem and Sugiyama, 1999).

Sugiyama et al. (1993) gave the optimal shape design to maximize the critical force of a cantilevered column, under the constraint of constant volume. Sugiyama et al. (2012) presented a realistic structural optimization of cantilevered columns subjected to a rocket-based follower force, with an experimental verification of the same. It was found that under realistic structural optimization, the flutter parameter of the shape designed column is approximately 1.2 times larger than that of the uniform (reference) column. The studies on the shape optimization of a column based on static buckling load and flutter behaviour are available in the literature, and are discussed. However, no such investigations based on the vibration behaviour of the optimized shape are found.

Again, the presence of damage is inevitable in a structure, both isotropic and composite. Extensive studies (Rahul and Datta, 2013) on the static and dynamic instability characteristics of structures having internal damage are found in the literature. However, the shape optimization of structural elements with internal flow is not available.

The present paper deals with the development of a realistic shape optimization of damaged columns that are subjected to conservative and non-conservative forces, using the Genetic algorithm (GA). The optimization was performed under the constraint of constant weight.

\section{Description of Problem}

\subsection{Finite Element Method of Formulation}

Let us consider a long slender damaged column of total length $\mathrm{L}$. It is discretized into $\mathrm{N}$ uniform elements of length $\mathrm{h}$. It is required to find the best shape of the column, with the weight constraint, for which: i. Static buckling problem: $\left(\mathrm{P}_{\mathrm{cr}}\right)_{\text {fundamental }}$ is maximum

ii. Vibrational problem: $\quad \omega_{\text {fundamental }}$ is maximum

iii. Flutter problem: $\quad \mathrm{P}_{\text {Flutter }}$ (Flutter-Load) is maximum

The elemental mass and stiffness matrices for the static buckling and vibrational problems are as follows (Cook et al. 1989):

Mass Matrix

$[\mathrm{M}]=\frac{\rho A_{o} h}{420} * \frac{A_{i}}{A_{o}}\left(\begin{array}{cccc}156 & 22 & 54 & -13 \\ 22 & 4 & 13 & -3 \\ 54 & 13 & 156 & -22 \\ -13 & -3 & -22 & 4\end{array}\right)$

Elastic Stiffness

$[\mathrm{K}]_{\mathrm{e}}=\frac{E I_{O}}{h^{3}} * \frac{I_{i}}{I_{o}}\left(\begin{array}{rrrr}12 & 6 & -12 & 6 \\ 6 & 4 & -6 & 2 \\ -12 & -6 & 12 & -6 \\ 6 & 2 & -6 & 4\end{array}\right)$

Geometric Stiffness

$[\mathrm{K}]_{\mathrm{g}}=\frac{P}{30 h}\left(\begin{array}{cccr}36 & 3 & -36 & 3 \\ 3 & 4 & -3 & -1 \\ -36 & -3 & 36 & -3 \\ 3 & -1 & -3 & 4\end{array}\right)$

For the analysis under conservative forces, a circular crosssection is considered. The boundary conditions considered are $\mathrm{C} / \mathrm{F}, \mathrm{C} / \mathrm{S}$, and $\mathrm{S} / \mathrm{S}$.

The non-conservative problem involves flutter, which is discussed in section 1 . The problem is described as a long slender column having a $\mathrm{C} / \mathrm{F}$ boundary condition, and is subjected to an end compressive follower force at the free end. A rectangular cross-section is considered for this problem. Fig. 1 describes the follower load problem of a slender column having a rectangular cross-section.

In Fig. 1, the mass per unit length of the column is denoted by $m$. It is assumed that $b$ is larger than $t$, in order to sustain vibrations in the $x-y$ plane $(b \geq t)$.

The formulation of load-stiffness matrix due to follower force is based on the equations of motion presented through Hamilton's principle, as follows:

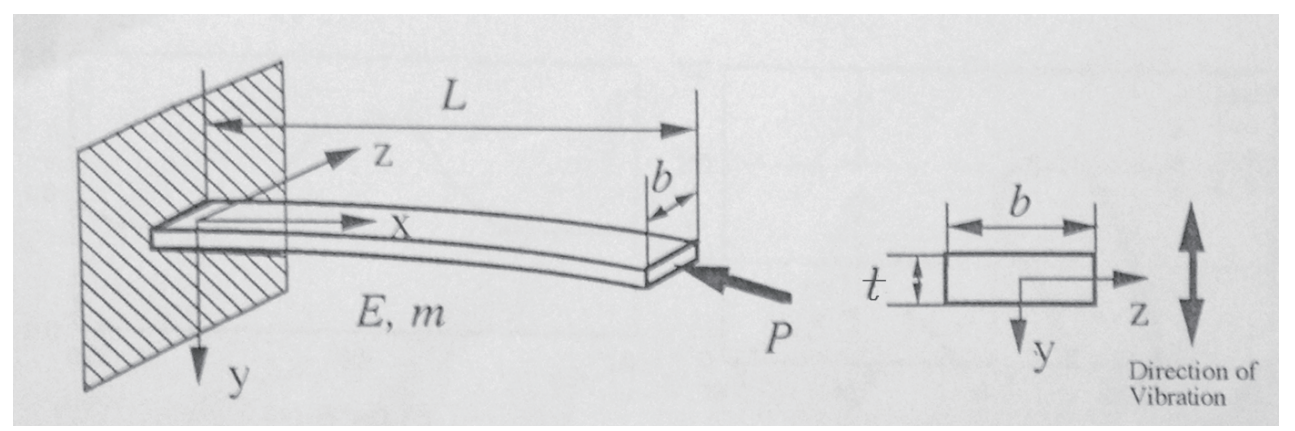

Fig. 1. Cantilevered column having a rectangular cross-section, and subjected to a follower force 


$$
\delta \int_{t_{1}}^{t_{2}}\left(T-V+W_{C}\right) d t+\int_{t_{1}}^{t_{2}} \delta W_{N C} d t=0
$$

where, $\mathrm{T}$ is the kinetic energy, $\mathrm{V}$ is the elastic potential energy, $\mathrm{W}_{\mathrm{C}}$ is the work done by the conservative component of the applied follower force, and $\delta \mathrm{W}_{\mathrm{NC}}$ is the virtual work done by the non-conservative component of the applied follower force. The Load- stiffness matrix can be expressed as:

Load Stiffness

$$
[K]_{\text {Load-stiffness }}=\frac{\eta P}{h}\left(\begin{array}{cccc}
0 & 0 & 0 & 0 \\
0 & 0 & 0 & 0 \\
0 & 0 & 0 & 1 \\
0 & 0 & 0 & 0
\end{array}\right)
$$

The terminologies for the matrices expressed above, which are required for the finite element formulation, are explained as follows:

$\mathrm{A}_{0}=$ C.S. Area of uniform-column element

$A_{i}=$ C.S. Area of ith element of stepped-column

$\mathrm{I}_{0}=$ Area moment of Inertia of uniform-column

$\mathrm{I}_{\mathrm{i}}=$ Area moment of Inertia of ith element of steppedcolumn

$\mathrm{h}=$ Length of each element

$\rho=$ Material Density

$\mathrm{E}=$ Young's Modulus of Elasticity

$\eta=$ Non-conservativeness parameter

\section{INCORPORATION OF DAMAGE PARAMETER}

The damage is incorporated element-wise in the column, as shown in Fig. 2, as per the following criteria:

i. Since weight is the constraint parameter for the optimization, the damage is incorporated in such a way that its total weight remains constant.

ii. Damage is imparted to the column at a specific location, by reducing the bending stiffness of the element. Damage of moderate intensity, which reduces the flexural rigidity of the element at the damagelocation at up to 0.5 times the bending stiffness of the undamaged uniform-column, is considered in the present analysis.

iii. Let $\mathrm{EI}_{0}$ be the bending stiffness of the undamaged uniform-column, and $\mathrm{EI}_{\mathrm{d}}$ be the bending stiffness of the damaged element. Then, according to the specified damage intensity-level, $\left(\mathrm{EI}_{\mathrm{d}} / \mathrm{EI}_{0}\right)=0.5$. iv. It is assumed that when damage occurs to the column, the density of material at the damage location changes, in order to fulfill the constant weight constraint. Fig. 2 shows the apparent position of damage in the column, where the density of the material is changed.
For undamaged element:
$\mathrm{m}=\rho \mathrm{A}$
For damaged element:
$\mathrm{m}=\lambda \rho \mathrm{A}$

Factor ' $\lambda$ ' is introduced in the above expression, to take care of the density changes at the damage location, while maintaining the constant weight constraint. A typical value of $\lambda$ is $\sqrt{2}$, when $\left[\mathrm{EI}_{\mathrm{d}} / \mathrm{EI}_{0}\right]=0.5$.

During the optimization process, no mass would be taken away, or be transferred to the damaged element for relocation. It would remain intact within the column.

\subsection{Formulation and Algorithm}

Constraint: The total weight of the column is constant CASE 1: STATIC (BUCKLING)

Let, $x_{i}=\frac{I_{i}}{I_{o}} \rightarrow \quad x_{i}=\frac{\pi r_{i}^{4} / 4}{\pi r_{o}^{4} / 4}=\left(\frac{r_{i}}{r_{o}}\right)^{4}$

The elastic stiffness would be a function of $\mathrm{x}$.

$[K]_{\mathrm{e}}=\frac{E I_{O}}{h^{3}} *\left[x_{i}\right]\left(\begin{array}{cccc}12 & 6 & -12 & 6 \\ 6 & 4 & -6 & 2 \\ -12 & -6 & 12 & -6 \\ 6 & 2 & -6 & 4\end{array}\right)$

The Eigenvalue problem to be solved is:

$\left|[\mathrm{K}(x)]_{e}-[\mathrm{K}]_{\mathrm{g}}\right|=0$

The geometric stiffness is a function of the load $\mathrm{P}$. Expressing the matrix in a slightly modified manner,

$[K]_{g} \rightarrow P *[K]_{g}$

The problem can be now be written as

$\left|[\mathrm{K}(x)]_{e}-\mathrm{P}[\mathrm{K}]_{\mathrm{g}}\right|=0$

Since the elastic stiffness depends on $\mathrm{x}$, the above equation will give different eigenvalues for different sets $[x]$. The eigenvalues are the critical buckling loads of the system.

Aim: To find the best set $\left[x_{i}\right](\forall \mathrm{i}=1$ to $\mathrm{N})$, so as to maximize the Buckling Load $\mathrm{P}_{\mathrm{cr}}$, while keeping the total

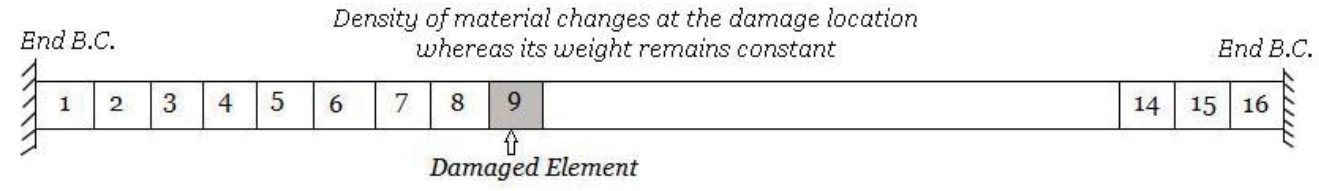

Fig. 2. Damaged column 
weight of the column unchanged.

The defining weight ratio for each element is:

$$
\overline{w_{i}}=\left(w_{i} / w_{0}\right) \quad(\forall \mathrm{i}=1 \text { to } \mathrm{N})
$$

where, $\quad w_{0}=$ weight per element of the uniform column $w_{\mathrm{i}}=$ weight of the $\mathrm{i}^{\text {th }}$ element of the steppedcolumn

The total weight of the column can be expressed as: $\sum_{i=1}^{N} w_{i}=N w_{0}=>\sum_{i=1}^{N} \overline{w_{i}}=N$.

Introducing new parameters $m_{i}(\forall \mathrm{i}=1$ to $\mathrm{N})$, where $m_{i}$ is assumed to be an integer, and $\Delta w$ is a step parameter, the weight of an element can be expressed as

$$
w_{i}=w_{\min }+m_{i} \Delta w
$$

or $\overline{w_{i}}=\overline{w_{\min }}+m_{i} \Delta \bar{w}$ (Dividing by $w_{0}$ )

where, $w_{\min }=$ Minimum weight of an element

Therefore, $\sum_{i=1}^{N} m_{i}=\sum_{i=1}^{N} \frac{\overline{w_{i}}-\overline{w_{\text {min }}}}{\Delta \bar{w}}$

$$
\sum_{i=1}^{N} m_{i}=\frac{N\left(1-\overline{w_{\min }}\right)}{\Delta \bar{w}}=\mathrm{M}
$$

$\mathrm{M}=$ The total number of parameters $\Delta \bar{W}$; and $\mathrm{M}$ is fixed.

Now,

Density = Mass per unit length/Cross-section Area (the length of each element is the same)

$\Rightarrow$ Mass per unit length $=$ Density * Area

$\Rightarrow$ Mass per unit Length is proportional to (radius) ${ }^{2}$

$$
\begin{array}{ll}
\Rightarrow \quad \frac{\mathrm{w}_{\mathrm{i}}}{\mathrm{w}_{0}}=\left(\frac{\mathrm{r}_{\mathrm{i}}}{\mathrm{r}_{\mathrm{o}}}\right)^{2} \\
\Rightarrow \quad x_{i}=\left(\frac{\mathrm{r}_{\mathrm{i}}}{\mathrm{r}_{\mathrm{o}}}\right)^{4}=\left(\frac{\mathrm{w}_{\mathrm{i}}}{\mathrm{w}_{\mathrm{o}}}\right)^{2} \quad \text { or } \quad x_{i}=\left(\overline{\mathrm{w}_{\mathrm{i}}}\right)^{2} \\
\Rightarrow \quad x_{i}=\left(\overline{w_{\min }}+m_{i} \Delta \bar{w}\right)^{2}
\end{array}
$$

It can be seen that for fixed values of $\overline{w_{\min }}$ and $\Delta \bar{w}, \overline{\mathrm{w}_{\mathrm{i}}}$ is a linear function of $m_{i}$. So, we need to find the best set [m], for which $\mathrm{P}_{\mathrm{cr}}$ is maximum, subject to constant $\mathrm{M}$.

\section{CASE 2: VIBRATIONAL}

Area Ratio $\frac{A_{i}}{A_{o}}=\frac{\pi r_{i}^{2}}{\pi r_{o}^{2}}=\left(\frac{r_{i}}{r_{o}}\right)^{2}$

Since, $x_{i}=\frac{I_{i}}{I_{o}}=\left(\frac{r_{i}}{r_{o}}\right)^{4} \quad \Rightarrow \quad \frac{A_{i}}{A_{o}}=\sqrt{x_{i}}$

The mass matrix would be a function of $\mathrm{x}$.

$[\mathrm{M}]=\frac{\rho A_{o} h}{420} \sqrt{x_{i}}\left(\begin{array}{cccc}156 & 22 & 54 & -13 \\ 22 & 4 & 13 & -3 \\ 54 & 13 & 156 & -22 \\ -13 & -3 & -22 & 4\end{array}\right)$

The Eigenvalue problem to be solved is:

$$
\begin{aligned}
& \left|-\omega^{2}[M(x)]+[K(x)]_{e}\right|=0 \\
& \Rightarrow \quad\left|M[(x)]^{-1}[K(x)]_{e}-\omega^{2} \mathrm{I}\right|=0
\end{aligned}
$$

Both Mass and Stiffness matrices are functions of $[x]$, and for every such possible set $[x]$, the characteristic equation will give different eigenvalues, which are simply the vibration frequencies of the system. As $\left[x_{i}\right]$ is dependent on $\left[m_{i}\right]$, as has already been explained in the previous case, the problem reduces to finding the best set $[m]$.

Aim: To find the best set $\left[m_{i}\right](\forall \mathrm{i}=1$ to $\mathrm{N})$, for which the fundamental Frequency is maximum, subject to constant $\mathrm{M}$.

\section{CASE 3: FLUTTER}

From eq. (1), the equation of motion for a non-conservative system can be expressed as

$$
[\mathrm{M}(\mathrm{x})]\{\ddot{\mathrm{X}}\}+[\mathrm{K}(\mathrm{x})]_{\mathrm{e}}\{\mathrm{X}\}-\left[\mathrm{K}_{\mathrm{g}}\right]\{\mathrm{X}\}+\left[\mathrm{K}_{\mathrm{L}}\right]\{\mathrm{X}\}=0
$$

where, $\left[K_{L}\right]$ involves the non-conservativeness parameter (Pradhan, Datta 2006), due to the follower force. The geometric and load stiffness matrices are written in a slightly modified manner, by taking the load $\mathrm{P}$ and nonconservativeness parameter $\eta$ outside of the matrices, as shown below.

$$
\begin{aligned}
{[K]_{g} } & \rightarrow P *[K]_{g} \\
{[K]_{L} } & \rightarrow(\eta P) *[K]_{L}
\end{aligned}
$$

Therefore, eq. (6) can be written as

$$
[\mathrm{M}(\mathrm{x})]\{\ddot{\mathrm{X}}\}+[\mathrm{K}(\mathrm{x})]_{\mathrm{e}}\{\mathrm{X}\}-\mathrm{P}\left(\left[\mathrm{K}_{\mathrm{g}}\right]-\eta\left[\mathrm{K}_{\mathrm{L}}\right]\right)\{\mathrm{X}\}=0
$$

For the purely applied follower force to the column, $\eta=1$. $\eta=0$ implies a conservative loading system. $\eta$ in the range 0 $\leq \eta \leq 1$ implies a follower load having a tangency parameter. Assuming the solution to eq. (7) in the form $\{X\}=\left\{X_{0}\right\} e^{i \omega t}$, eq. (7) reduces to:

$$
\left([\mathrm{K}(\mathrm{x})]_{\mathrm{e}}-\mathrm{P}\left(\left[\mathrm{K}_{\mathrm{g}}\right]-\eta\left[\mathrm{K}_{\mathrm{L}}\right]\right)-\omega^{2}[\mathrm{M}(\mathrm{x})]\right)\left\{X_{0}\right\}=0
$$

The stability of the system is determined by investigating the nature of the eigenvalue $\omega$, which is complex in nature.

Case I: $\quad \operatorname{Im}(\omega) \geq 0 ; \quad$ Stable.

Case II: $\quad \operatorname{Im}(\omega)<0$ and $\operatorname{Re}(\omega)=0$; Divergence type of instability.

Case III: $\quad \operatorname{Im}(\omega)<0$ and $\operatorname{Re}(\omega) \neq 0$; Flutter type of instability.

Again, it can be seen that elastic-stiffness and mass matrices are functions of $\left[\mathrm{x}_{\mathrm{i}}\right]$ similar to the previous cases, and $\left[\mathrm{x}_{\mathrm{i}}\right]$ is dependent on $\left[\mathrm{m}_{\mathrm{i}}\right]$, as discussed before. So, for the flutter analysis also, we need to find the best set $[m]$, which 
maximizes the Flutter Load of the column, under constant weight constraint.

\section{SHAPE OPTIMIZATION USING GA}

i. An initial set $[m]$ is generated randomly in the beginning, such that the elements of the set satisfy the constant weight criterion: $\left[\sum_{i=1}^{N} m_{i}=\mathrm{M}\right]$

$\mathrm{M}$ is constant, and explicitly defined.

ii. Generation of the initial Population of strings: An initial population of strings is generated in a random manner. The number of generated strings is represented by $S$. Each string contains the information pertaining to the weight transfer from one element to another element. Two finite numbers are encoded in binary form for each string. An additional bit is added to the string, which contains the information related to the direction of weightshift. If it is 0 , it represents backward shift; and if it is 1 , it represents forward shift. If the number of elements $\mathrm{N}=16$, then 4 bits are required to represent the position of an element, because $(16)_{10}=(1111)_{2}$. So, each string contains 9 bits, in which the first and last four bits represent the element numbers between which weight transfer takes place, and the middle bit represents the direction of weight shift. For instance, the string 010010111 represents the movement of $\Delta w$ from the $5^{\text {th }}\left(=2^{2}+1\right)$ element, to the $8^{\text {th }}\left(=2^{2}+2^{1}+2^{0}+1\right)$ element. The middle bit is 1 , which represents that the weight transfer takes place in the forward direction, from the $5^{\text {th }}$ to the $8^{\text {th }}$ element. If it is 0 , then $\Delta w$ would be shifted from the $8^{\text {th }}$ to the $5^{\text {th }}$ element (backward direction), based on certain conditions.

iii. Before the transference of weight from the $\mathrm{i}^{\text {th }}$ element to the $\mathrm{j}^{\text {th }}$ element, it is checked whether $m_{i}=0$ or $m_{i} \neq 0$, and $i=j$ in the string. In both these cases, no weight shifting is done, and the next string is examined.

iv. When the string doesn't fall under any category, as explained in step iii, i.e. $m_{i} \neq 0$ and $i \neq j$ in the string, then movement is performed, and the value of the optimization-function is computed, according to the new set $[m]$. For the static and vibration problem, the optimization-function is the buckling load and vibration frequency, respectively. For the followerforce problem, the optimization-function is the Flutter load. Again, two possibilities arise. The value of the optimization-function increases or decreases. If the optimization-function increases, then the new distribution of weights is updated, and stored as the latest set $[m]$. If it decreases, then $\Delta w$ is restored back to its previous location. v. FITNESS EVALUATION: The fitness value of each string is computed and stored. The fitness value of a string is essentially the value of the optimization-function obtained, when the weight transfer takes place according to the string. Those strings with high fitness values are considered as healthy parents.

vi. REPRODUCTION: After the storage process, the evolutionary operation of GAs (Pratihar, 2008) is applied to the population of strings. Reproduction is the first step of evolution. Not all the GA-strings contained in the population may be of equal worth, in terms of their fitness values. In this step, good strings are selected from the overall population, based on their fitness information.

SELECTION SCHEME USED: Proportionate selection/ Roulette-Wheel Selection

In this scheme, the probability of a string to be selected in the mating pool is considered to be proportional to its fitness. This is implemented with the help of a Roulette wheel, as shown in Fig. 3. The top surface area of the wheel is divided into $S$ parts $(S=$ population size), in proportion to the fitness values $\mathrm{f}_{1}, \mathrm{f}_{2} \ldots \mathrm{f}_{\mathrm{n}}$. The wheel is rotated in a particular direction, and after it stops, a fixed pointer is used to indicate the winning area. A particular sub-area representing a GA-solution is probabilistically selected to be the winner, and the probability that the $\mathrm{i}^{\text {th }}$ area will be declared so, is given by the following expression:

$$
P=f_{i} / \sum_{i=1}^{S} f_{i}
$$

where, $f_{i}=$ the fitness value of the $\mathrm{i}^{\text {th }}$ string

The wheel is rotated $\mathrm{N}$ times, and each time, only one area is identified by the pointer to be the winner. In this scheme, a good string is selected a number of times. This process results in the generation of a mating pool.

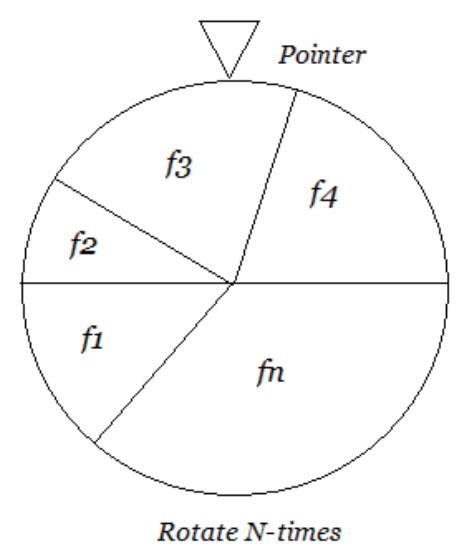

Fig. 3. Roulette Wheel 
vii CROSSOVER: In crossover, there is an exchange of properties between two parents, as a result of which, two children solutions are produced. To carry out this operation, the parents or mating pairs (each pair consists of two strings) are selected at random from the mating pool. A total of $S / 2$ mating pairs are formed, from a population of strings of size $S$. The parents are checked as to whether they will participate in crossover or not, by tossing a coin, whose probability of appearing heads is $\mathrm{P}_{\mathrm{c}}$. If heads appears, the parent participates in crossover, to produce two children. Otherwise, they remain intact in the population. A number lying between 0 and 1 is generated, using a random number generator. If the random number is smaller than, or equal to $\mathrm{P}_{c}$, the outcome of coinflipping is considered as true; else it is false.

Once a particular mating pair is selected for crossover, the crossing site is decided using a random number generator, by generating an integer lying between 1 and (L-1), where $\mathrm{L}$ is the length of string. In our case, $\mathrm{L}=9$, because each string is made up of 9 bits.

A Single Point Cross Over scheme is used in our Analysis. A crossover site lying between 1 and (L-1) is selected randomly, as explained above. The left side of the crossover site is left unaltered, and swapping is done between the two substrings lying on the right side of the crossover site.

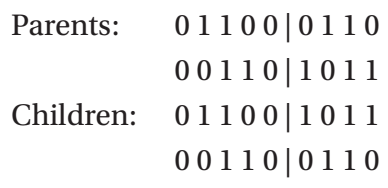

viii MUTATION: The concept of mutation is applied, in which 1 is converted to 0 , and vice versa. The role of mutation is to push a string from a local basin of solutions, to a global basin of solutions. The probability of mutation is kept low, to avoid random search.

The maximum number of generations is defined, depending upon some terminating criteria. The best possible set $[m]$ is obtained from the final generation of strings. Fig. 4 shows a schematic diagram of the working cycle of GA, as explained in the above steps.

\section{Results and Discussion}

The results are presented on the basis of the dimensions of the column, as follows:

Static and Vibrational analysis (Circular cross-section)

$\begin{array}{ll}\text { Material } & =\text { Steel } \\ \text { Young's Modulus (E) } & =2.056 \times 10^{11} \mathrm{~N} / \mathrm{m}^{2} \\ \text { Density of Material } & =7800 \mathrm{Kg} / \mathrm{m}^{3} \\ \text { Total Length of Column } & =1 \mathrm{~m} \\ \text { Diameter of Uniform Column } & =100 \mathrm{~mm}\end{array}$

Diameter of Uniform Column (D0) $=100 \mathrm{~mm}$

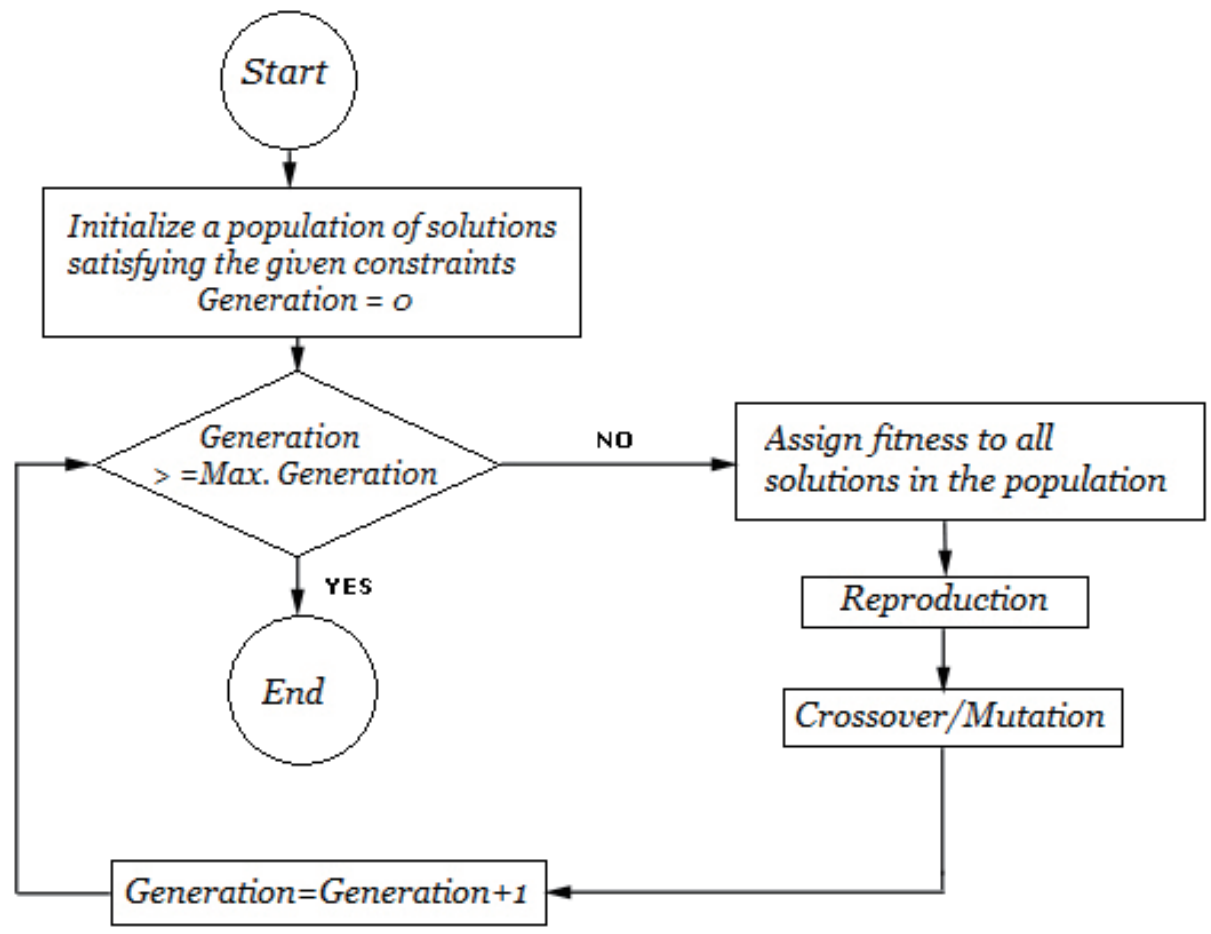

Fig. 4. Schematic Diagram showing the working cycle of a GA 
Flutter Analysis (Rectangular cross-section)

Material

Young's Modulus (E)

Density of Material
$=$ Steel

$=2.056 \times 10^{11} \mathrm{~N} / \mathrm{m}^{2}$

$=7800 \mathrm{Kg} / \mathrm{m}^{3}$
Total Length of Column

$=1 \mathrm{~m}$

Width of uniform column, b0

$=10 \mathrm{~cm}$

Thickness of uniform column, t0 $=1 \mathrm{~cm}$

Table 1. Comparison between buckling load values of uniform and optimized undamaged columns, under various end restraints (Static Analysis)

\begin{tabular}{|c|c|c|c|c|}
\hline $\begin{array}{l}\text { Boundary } \\
\text { Condition }\end{array}$ & Mode Number & $\begin{array}{c}\text { Uniform } \\
\text { Column } \\
{[1 \mathrm{e}+06 \text { Newton }]}\end{array}$ & $\begin{array}{c}\text { Optimized } \\
\text { Column } \\
{[1 \mathrm{e}+06 \text { Newton }]}\end{array}$ & $\begin{array}{c}\text { Percentage } \\
\text { Increase in Pcr }(\%)\end{array}$ \\
\hline \multirow{3}{*}{$\mathbf{C} / \mathbf{F}$} & 1 & 2.4927 & 3.291 & 32.03 \\
\hline & 2 & 22.4097 & 28.9354 & 29.12 \\
\hline & 3 & 62.2608 & 78.2717 & 25.72 \\
\hline \multirow{3}{*}{$\mathrm{C} / \mathrm{S}$} & 1 & 20.378 & 26.6033 & 30.55 \\
\hline & 2 & 60.235 & 75.2610 & 24.94 \\
\hline & 3 & 120.033 & 146.593 & 22.13 \\
\hline \multirow{3}{*}{$\mathbf{S} / \mathbf{S}$} & 1 & 9.9606 & 12.9706 & 30.22 \\
\hline & 2 & 39.8444 & 50.2884 & 26.21 \\
\hline & 3 & 89.6615 & 109.0527 & 21.63 \\
\hline
\end{tabular}

Table 2. Comparison between Vibration frequencies of uniform and optimized undamaged columns, for various BCs (Vibrational Analysis)

\begin{tabular}{|c|c|c|c|c|}
\hline $\begin{array}{l}\text { Boundary } \\
\text { Condition }\end{array}$ & Mode Number & $\begin{array}{c}\text { Uniform } \\
\text { Column } \\
{[1 \mathrm{e}+03 \mathrm{rad} / \mathrm{s}]}\end{array}$ & $\begin{array}{c}\text { Optimized } \\
\text { Column } \\
{[1 \mathrm{e}+03 \mathrm{rad} / \mathrm{s}]}\end{array}$ & $\begin{array}{c}\text { Percentage } \\
\text { Increase in } \omega(\%)\end{array}$ \\
\hline $\mathbf{C} / \mathbf{F}$ & $\begin{array}{l}1 \\
2 \\
3\end{array}$ & $\begin{array}{l}0.451 \\
2.828 \\
7.919\end{array}$ & $\begin{array}{l}1.4724 \\
4.8377 \\
15.161\end{array}$ & $\begin{array}{l}226.26 \\
71.06 \\
91.45\end{array}$ \\
\hline $\mathrm{C} / \mathrm{S}$ & $\begin{array}{l}1 \\
2 \\
3\end{array}$ & $\begin{array}{l}1.979 \\
6.413 \\
13.38\end{array}$ & $\begin{array}{l}2.7969 \\
10.152 \\
18.727\end{array}$ & $\begin{array}{l}41.33 \\
58.29 \\
39.94\end{array}$ \\
\hline $\mathbf{S} / \mathbf{S}$ & $\begin{array}{l}1 \\
2 \\
3\end{array}$ & $\begin{array}{l}1.2668 \\
5.0672 \\
11.402\end{array}$ & $\begin{array}{l}1.3410 \\
5.3649 \\
12.151\end{array}$ & $\begin{array}{l}5.857 \\
5.875 \\
6.569\end{array}$ \\
\hline
\end{tabular}




\section{CASE I: NO DAMAGE}

Static and Vibrational Analysis:

Table 1 shows a comparison between the buckling load values of uniform and optimized undamaged columns, under various end restraints, for the first three modes of buckling. It can be seen that the optimized shape column has higher buckling loads, for all boundary conditions. Similarly, Table 2 shows a comparison between the vibration frequencies of uniform and optimized undamaged columns, under various end restraints, for the first three modes of vibration. Fig. 5 shows the optimized shapes for the undamaged column (circular cross section), having different boundary conditions, based on static and vibrational analysis. The results show that under static and vibrational analysis, the optimized shape of the undamaged column for
$\mathrm{C} / \mathrm{F}$ and S/S boundary conditions possesses a wider part at the midspan. For the case of the $\mathrm{C} / \mathrm{S}$ boundary condition, the midspan gets narrower.

\section{Flutter Analysis:}

Flutter analysis for the optimized shape of the column was carried out with a rectangular cross-section, for the clamped-free (C/F) boundary condition, subjected to non-conservative follower load (Fig. 1). For the optimized column, the best $m_{i}$ distribution (element wise) is as follows:

$$
\begin{aligned}
& {[m]=\left[\begin{array}{llllllllllllllll}
23 & 12 & 4 & 13 & 25 & 32 & 36 & 31 & 37 & 31 & 27 & 20 & 8 & 12 & 0 & 9
\end{array}\right] ;} \\
& {[\bar{W}]=\left[\begin{array}{llllll}
1.1350 & 0.6400 & 0.2800 & 0.6850 & 1.2250 & 1.5400
\end{array}\right.} \\
& \begin{array}{llllll}
1.7200 & 1.4950 & 1.7650 & 1.4950 & 1.3150 & 1.0000
\end{array} \\
& \left.\begin{array}{llll}
0.4600 & 0.6400 & 0.1000 & 0.5050
\end{array}\right] \text {; }
\end{aligned}
$$

It is observed that the flutter load for the uniform column

\section{Static Analysis}

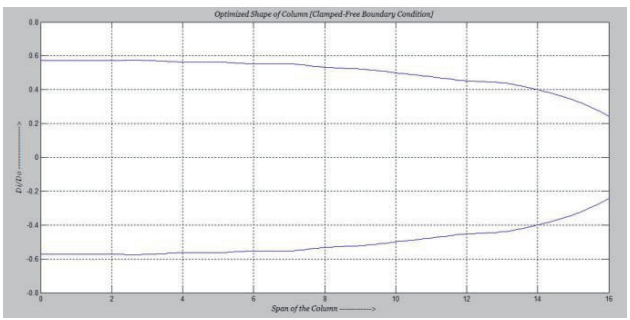

Clamped-Free (C/F)

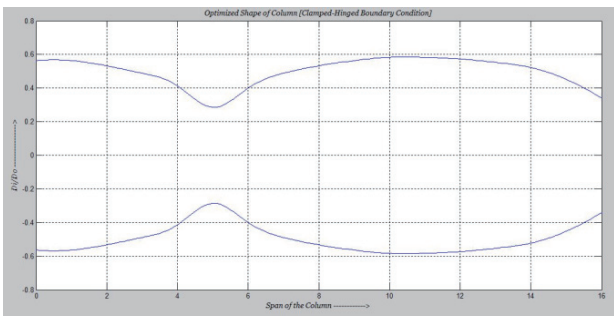

Clamped-Simply supported (C/S)

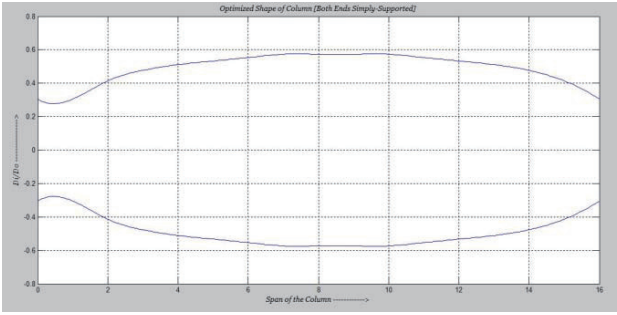

Simply supported (S/S)

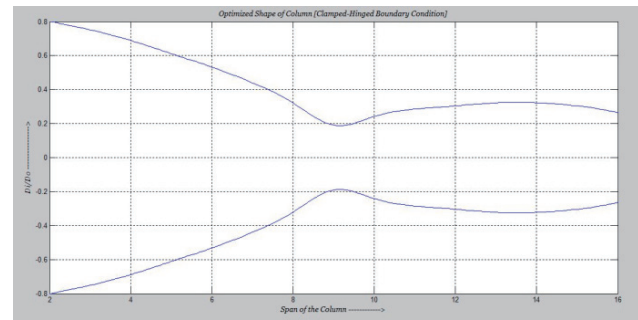

Clamped-Simply supported (C/S)

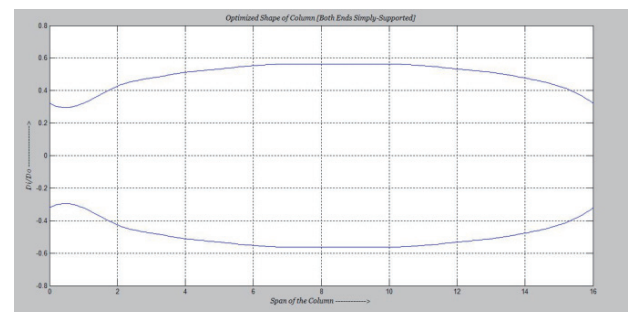

Simply supported $(\mathrm{S} / \mathrm{S})$

Fig. 5. Optimized shapes for the undamaged circular cross-section column, under Static and Vibrational analysis (Fundamental modes) 
is around $36,000 \mathrm{~N}$; whereas, for the optimized column, the flutter load is found to be around $82,000 \mathrm{~N}$, which is 2.28 times the flutter-load value of the uniform column. Fig. 6 shows the optimized shape for the undamaged column (rectangular cross-section), having a clamped-free (C/F) boundary condition, based on flutter analysis. The optimal shape of the column under flutter analysis shows that the column has a wide part at the midspan, and a narrow part at the tip.

This result compares well with the results presented by
Sugiyama et al. (1993).

\section{CASE II: DAMAGE}

Static and Vibrational Analysis:

Table 3 shows a comparison between the buckling load values of uniform and optimized damaged columns, under various end restraints, for the first three modes of buckling. Table 4 shows a comparison between the vibration frequencies of uniform and optimized damaged columns, under various end restraints, for the first three modes of

Table 3. Comparison between buckling load values of uniform and optimized damaged columns, under various end restraints (Static Analysis)

\begin{tabular}{|ccccc|}
\hline $\begin{array}{c}\text { Boundary } \\
\text { Condition }\end{array}$ & Mode Number & $\begin{array}{c}\text { Uniform } \\
\text { Column with } \\
\text { damage } \\
{[1 \mathrm{e}+06 \text { Newton }]}\end{array}$ & $\begin{array}{c}\text { Optimized } \\
\text { Column with } \\
\text { damage } \\
{[1 \mathrm{e}+06 \text { Newton }]}\end{array}$ & $\begin{array}{c}\text { Percentage } \\
\text { Increase in Pcr (\%) }\end{array}$ \\
\hline C/ $\mathbf{F}$ & 1 & 2.358 & 3.0423 & 29.02 \\
& 2 & 20.755 & 26.419 & 27.29 \\
\hline C/S & 3 & 60.253 & 74.909 & 24.32 \\
& 1 & 18.571 & 23.526 & 26.68 \\
& 2 & 58.612 & 72.124 & 23.05 \\
\hline S/S & 3 & 109.556 & 137.077 & 25.12 \\
& 1 & 8.844 & 11.004 & 24.42 \\
& 2 & 39.603 & 48.445 & 22.33 \\
& 3 & 80.955 & 100.602 & 24.27 \\
\hline
\end{tabular}

\section{Flutter Analysis}

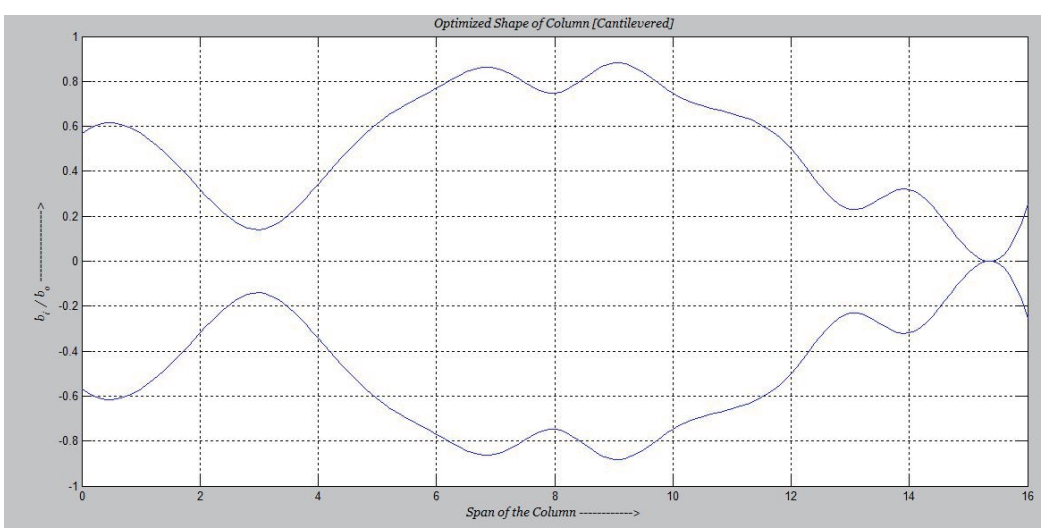

Fig. 6. Optimized shape for the undamaged rectangular cross-section column, under Flutter Analysis (Fundamental mode) 
vibration. It can be seen that the incorporation of damage in the column results in reduction of the buckling load and vibration frequencies for the optimized damaged column, as compared to the optimized undamaged column.

Fig. 7 shows the optimized shapes for the damaged column (circular cross-section) having different boundary conditions, based on buckling and vibrational analysis. It is observed that the optimized shapes of the damaged column for static and vibrational cases remain similar to those of the undamaged column. From the results, it can be concluded that the column having the highest values of $\mathrm{P}_{\mathrm{cr}}$ (the static case) and $\omega$ (the vibrational case) has a unique shape corresponding to each boundary condition, and the incorporation of damage in the column only alters that shape to a certain extent. The overall geometry of the column remains nearly the same. This result holds true for moderate intensity-level damage. When the damage is severe i.e. $\left(\mathrm{EI}_{\mathrm{d}} / \mathrm{EI}_{0}\right)<0.5$, then the optimized shapes may be entirely different.

\section{Flutter Analysis:}

Similar to the case of undamaged column, flutter analysis was carried out for the damaged column having a rectangular cross-section, for clamped-free (C/F) boundary condition, to find the optimized shape column with maximum flutter load. For the optimized damaged column, the best $m_{i}$ distribution (element-wise) is as follows:

$$
\begin{aligned}
& {[m]=\left[\begin{array}{llllllllllllllll}
23 & 12 & 4 & 13 & 25 & 32 & 35 & 31 & 20 & 31 & 27 & 20 & 9 & 12 & 0 & 9
\end{array}\right] \text {; }} \\
& {[\bar{w}]=\left[\begin{array}{llllll}
1.1350 & 0.6400 & 0.2800 & 0.6850 & 1.2250 & 1.5400
\end{array}\right.} \\
& \begin{array}{llllll}
1.6750 & 1.4950 & 1.0000 & 1.4950 & 1.3150 & 1.0000
\end{array} \\
& \left.\begin{array}{lllll}
0.5050 & 0.6400 & 0.1000 & 0.5050
\end{array}\right] \text {; }
\end{aligned}
$$

It is observed that the flutter load for the uniform damaged column is around $30,000 \mathrm{~N}$; whereas, for the optimized damaged column, it is around $58,000 \mathrm{~N}$. The shape optimization has enhanced the flutter load of the column to 1.93 times the flutter load of the uniform column. It is clear from previous observations that the incorporation of damage in the column reduces its strength. Here also, the same fact is observed. For the optimized undamaged column, the flutter load rises to 2.28 times the flutter load value of the uniform column; whereas, including damage in the column only reduces the load increment for the optimized shape by up to 1.93 times.

The values of $\mathrm{P}_{\text {cr }}$ and $\omega$ for the optimized damaged column are comparatively lower, than those of the optimized undamaged column. For example, for the $\mathrm{C} / \mathrm{F}$ condition, the critical buckling load for the optimized undamaged column is $32.03 \%$ higher than that of the uniform undamaged column. Whereas, for the damaged column, the optimized shape has

\begin{tabular}{|c|c|c|c|c|}
\hline & & Uniform & Optimized & \\
\hline $\begin{array}{l}\text { Boundary } \\
\text { Condition }\end{array}$ & Mode Number & $\begin{array}{c}\text { Column with } \\
\text { damage } \\
{[1 \mathrm{e}+03 \mathrm{rad} / \mathrm{s}]}\end{array}$ & $\begin{array}{l}\text { Column with } \\
\text { damage } \\
{[1 \mathrm{e}+03 \mathrm{rad} / \mathrm{s}]}\end{array}$ & $\begin{array}{c}\text { Percentage } \\
\text { Increase in } \omega(\%)\end{array}$ \\
\hline \multirow{3}{*}{$\mathrm{C} / \mathrm{F}$} & 1 & 0.446 & 1.4374 & 222.19 \\
\hline & 2 & 2.665 & 4.5793 & 71.85 \\
\hline & 3 & 7.878 & 14.727 & 86.93 \\
\hline \multirow{3}{*}{$\mathrm{C} / \mathrm{S}$} & 1 & 1.893 & 2.5230 & 33.25 \\
\hline & 2 & 6.399 & 9.5068 & 48.57 \\
\hline & 3 & 12.71 & 17.115 & 34.63 \\
\hline \multirow{3}{*}{$\mathbf{S} / \mathbf{S}$} & 1 & 1.195 & 1.2353 & 3.36 \\
\hline & 2 & 5.053 & 5.3060 & 5.02 \\
\hline & 3 & 10.87 & 11.705 & 7.71 \\
\hline
\end{tabular}
a $\mathrm{P}_{\mathrm{cr}}$ value that is only $29.02 \%$ higher than that of the uniform damaged column, for the same boundary condition. So, it

Table 4. Comparison between Vibration frequencies of uniform and optimized damaged columns, for various BCs (Vibrational Analysis) 
can be concluded that up to a certain extent, $\mathrm{P}_{\mathrm{cr}}$ and $\omega$ values for the optimized column decrease, with the increase in the damage intensity level. The result is always affirmative for the fundamental mode. For higher modes, it may, or may not, be true. A similar kind of behaviour is observed in the case of non-conservative loading. The damage only modified the geometry of the optimized column up to a certain extent. The overall nature of the shape remained the same, i.e. wider at the midspan, and narrower at the free end. Again, this result holds good only for low intensity damage.

\section{Concluding Remarks}

The optimal design problem of damaged columns that are subjected to conservative and non-conservative forces has been investigated, to find the optimal shape of the columns, with maximum buckling load, vibrational frequency, and flutter load as the parameters. The constraint is constant weight, and is formulated by considering the fundamental modes. Damage is incorporated into the column at a specific location, by reducing the bending stiffness of the element. It has been concluded that for moderate intensity damage, the optimized shapes of the damaged column remain similar to those of the optimized undamaged column. The values of $P_{c r}, \omega$, and flutter load for the optimized damaged column are comparatively lower, than those of the optimized undamaged column.
Static Analysis

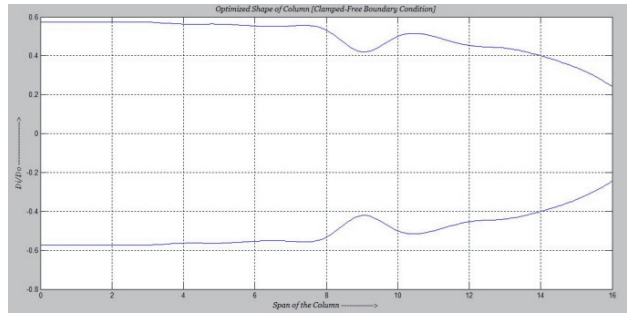

Clamped-free $(\mathrm{C} / \mathrm{F})$

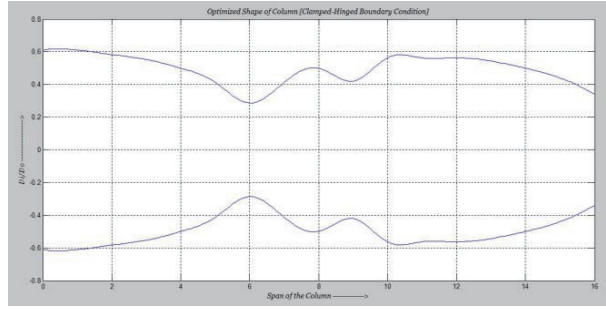

Clamped-Simply supported (C/S)

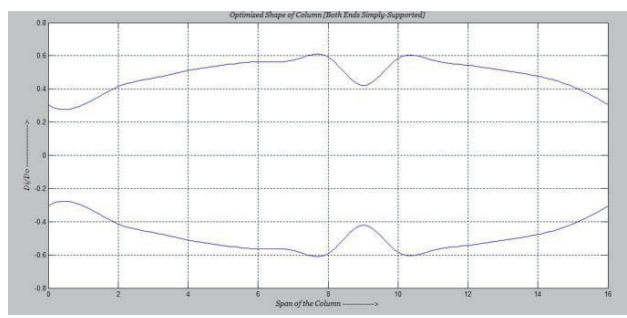

Simply supported (S/S)

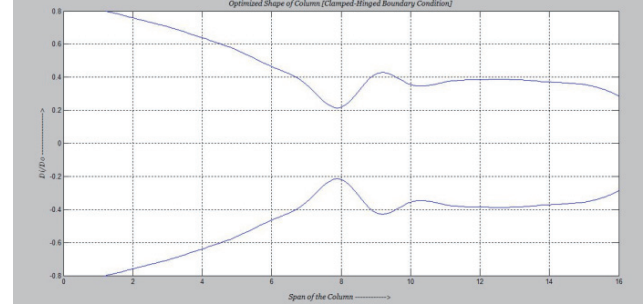

Clamped-Simply supported (C/S)

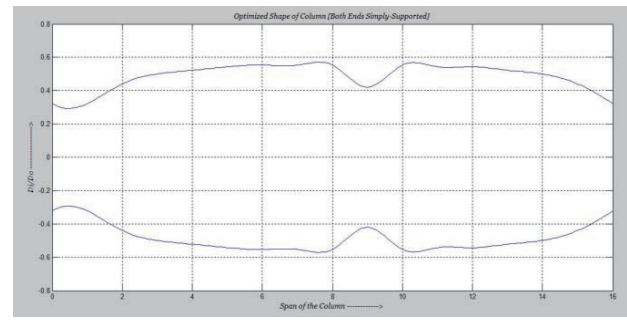

Simply supported (S/S)

Fig. 7. Optimized shapes for damaged circular cross-section column, under Static and vibrational analysis (Fundamental modes) 


\section{References}

[1] Bolotin, V. V., "Non-conservative problems of the Theory of Elastic Stability”, Oxford: Pergamon Press, Oxford, 1963.

[2] Evan-Ivanowski, “Resonant Oscillations in Mechanical systems”, Elsevier, New York, 1976.

[3] Elishakoff, I., "Controversy associated with the so called follower forces", Applied Mechanics reviews, Vol. 58, No. 2, 2005, pp. 117-142.

[4] Sugiyama, Y., Langthjem, M. and Ryu, B., "Realistic follower forces", J. Sound Vib, Vol. 225, No. 4, 1999, pp.779782 .

[5] Datta, P. K., and Biswas, S., "Aeroelastic behaviour of Aerospace structural elements with follower forces: A review", Int' l J. of Aeronautical \& space Sci, Vol. 12, No. 2, 2011, pp. 134-148.

[6] Hanaoka, M., and Washizu, K., "Optimum Design of Beck's column”, Comp Struct, Vol. 11, 1980, pp. 473-480.

[7] Langthjem, M. A., and Sugiyama, Y., "Optimum design of Beck's column with a constraint on the static buckling load", Struct. Optim, Vol. 18, 1999, pp. 228-235.

[8] Ishida, R., and Sugiyama, Y., "Proposal of Constructive algorithm and discrete shape design of the strongest column",
AIAA J, Vol. 33, No.3, 1995, pp. 401-406.

[9] Sugiyama, Y., and Katayama, T., Ryu, B. and Horii, R., "Optimal shaped design of cantilevered columns subjected to a follower force”, Proceedings of The 1993 Asia-Pacific Vibration Conference, Kitakyushu, Japan, pp. 1746-1751.

[10] Sugiyama, Y., Langthjem, M. A., Iwama, T. Kobayashi, M., Katayama, M., and Yutani, H., "Shape optimization of cantilevered columns subjected to a rocket based follower force and its experimental verification", Struct. Multidisc. Optim, Vol. 46, 2012, pp. 829-838.

[11] Rahul, R., and Datta, P. K., "Static and Dynamic instability characteristics of thin plate like beam with internal flow subjected to in-plane harmonic load", Int'l J. of Aeronautical \& Space Sci, Vol. 14, No.1, 2013, pp. 19-29.

[12] Cook, R. D., Malkus, D. S., and Plesha, M. E., Concepts and applications of finite element analysis, Wiley, New York, 1989.

[13] Pradhan, S., and Datta, P. K., "Dynamic instability characteristics of a free-free missile structure under a controlled follower force", Aircraft Engineering and Aerospace Technology, Vol. 78, No. 6, 2006, pp. 509-514.

[14] Pratihar, D. K., Soft Computing, Narosa Publishing House, New Delhi, 2008. 